\title{
El desplazamiento de la cuestión de la ideología en el pensamiento de Alain Badiou
}

\author{
The shift of the ideology question in Alain Badiou's thought
}

\section{Leandro García Pon₹o*}

\begin{abstract}
Resumen: Alain Badiou ha culminado recientemente lo que él mismo ha dado en llamar su "obra capital". Se trata de los tres tomos de El ser y el acontecimiento. Allí despliega rigurosamente su ontología matemática, su lógica del aparecer y un tratamiento exhaustivo de las verdades desde un punto de vista inmanente. A lo largo de todo este eje vertebrante, con excepción de algunos pasajes del primer tomo, la cuestión de la ideología está ausente. Deberemos atender a los textos tempranos y a algunos de coyuntura más recientes para rastrearla y escrutar su sentido. En el presente trabajo intentamos desarrollar una explicación genética para esta ausencia a la vez que pretendemos vincularla con un desplazamiento entre dos puntos de vista en la producción de ciencia. Entendemos, además, que el mentado desplazamiento es pasible de ser reconducido a los diferentes contextos de producción -especialmente políticos- que ha atravesado el conjunto de la obra badiouana.
\end{abstract}

Palabras clave: ideología, ontología, política, ciencia, representación

Abstract: Alain Badiou has recently completed what he himself has called his "capital work". These are the three volumes of Being and event. There, he rigorously unfolds his mathematical ontology, his logic of appearing and an exhaustive treatment of truths from an immanent point of view. Throughout this axis, with the exception of some passages from the first volume, the question of ideology is absent. We will have to consider the early texts and some of the more recent conjuncture ones to trace and think its meaning. In this paper we try to develop a genetic explanation for this absence while we try to link it with a shift between two points of view in the production of science. We also understand that this shift can be taken back to the different

* Doctor en Filosofía (UNC) bajo la tutela de Diego Tatián y Alain Badiou, se desempeña actualmente como Profesor Asistente en la Cátedra de Filosofía Antigua de la Facultad de Filosofía y Humanidades de la Universidad Nacional de Córdoba (Argentina). Ha publicado tres libros (La fundación de una ciudad. Sobre la introducción de las matemáticas en la filosofía de Platón; Badiou. Una introducción y el reciente Alain Badiou. Política de la Idea). Dirección electrónica: leagarciaponzo@gmail.com 
production contexts -especially the political ones- that the badiouan work has gone through.

Keywords: ideology, ontology, politics, science, representation

\section{Delimitación e hipótesis}

En la secuencia abierta por El ser y el acontecimiento ${ }^{1}$ - prevista en cierta medida por la Teoría del Sujeto- ${ }^{2}$ se produce un aparente alejamiento de la preocupación política de la filosofía al mismo tiempo que un abandono del andamiaje conceptual y la retórica marxistas. ${ }^{3}$ Una de las condiciones de este viraje es un desconocimiento deliberado -e ideológico- de la historia de la filosofía y una redefinición del propio concepto de historia, que ha sido objeto de investigaciones precedentes y que no será tratado aquí. ${ }^{4} \mathrm{La}$ segunda condición, relativa a la cuestión de la ideología, se ubica en el campo problemático que pone al llamado pensamiento "post-estructuralista" a medir su talla y pertenencia con la tradición marxista.

En el siguiente trabajo intentamos mostrar que esta variación está posibilitada por un recubrimiento ideológico que impide ver un desplazamiento entre un punto de vista proletario de la ciencia y uno burgués, que entraña, a su vez, un abandono de la propia noción de ideología.

1 Alain Badiou, L'être et l'événement, Seuil, Paris, 1988. [Trad. castellana: El ser y el acontecimiento, Buenos Aires, Manantial, 1999].

2 Alain Badiou, Théorie du sujet, Seuil, Paris, 1990. [Trad. castellana: Teoría del sujeto, Buenos Aires, Prometeo, 2008].

${ }^{3}$ En lo que concierne al presente trabajo, es central en esta etapa el libro de Badiou en co-autoría con F. Balmès De l'ideologie (Paris, Maspero, 1976). Respecto del desplazamiento en sí mismo, cfr. Bruno Bosteels, Badiou o el recomienzo del materialismo dialéctico, Santiago de Chile, Palinodia, 2007.

${ }^{4}$ Cfr. especialmente el prólogo de Alain Badiou, La filosofía, otra vez, Madrid, Errata Naturae, 2010. Allí se tramita la posibilidad de que la de-sutura de la filosofía respecto de la política reside en la identificación de una/s instancia/s de sutura previa, de sus motivos históricos y de la necesidad, histórica también, de sobrepasarla, fundamentalmente a través de la identificación de la ontología con las matemáticas. 


\section{Perspectiva exterior: ideología, estrategia y eficacia}

Es probable que, más allá de su labor especulativa, la gran virtud de Badiou provenga de su enorme capacidad estratégica para tornar su filosofía un producto ideológicamente eficaz. Dicha capacidad estratégica depende de un tipo de conciencia sobre la historia, estructural, que es a-histórica tomada por sí misma. Es decir: los pensamientos que producen efectos considerables se muestran como trans-epocales por exhibir un grado de percepción máximo del momento de la historia en el que les toca anidar. Están, en términos hegelianos, a la altura de la época.

Esta forma peculiar de la conciencia histórica de la filosofía reúne dos rasgos esenciales y complementarios: (1) nunca puede pronunciarse del todo; en cuanto se expone en exceso se disuelve su capacidad comunicativa, pues depende en gran medida de no exponer que se sabe que hay una intencionalidad persuasiva a la base de todo; (2) puede percibirse por lo general en (a) variaciones epocales de una obra (como lo que sucede entre el Badiou de los setenta, el de fines de los ochenta y el de la primera década del presente siglo) o en (b) el registro formal de una obra, es decir, el tipo de textos que la tejen. En este caso, los textos contraperiodísticos de Badiou son un indicador de una necesidad de penetración ideológica, pues en ellos encontramos una muy sutil mixtura de sentencias universalmente accesibles, de análisis de casos políticos concretos y actuales y una referencia continua y simple a los pilares de su filosofía. Los textos literarios son otro de estos casos. Su teatro, pensado como teatro "infantil" con una clara vocación pedagógica, por ejemplo. Pero el caso más evidente es el de La República de Platón, donde monta una ficción con el solo propósito de replantear las vías para el comienzo de una nueva política. Como suele sostener nuestro filósofo a partir del dictum lacaniano: una verdad está siempre en una estructura de ficción (y de fijación también). Se puede presentar una verdad, dice Badiou, "con una parte de ficción, incluso si es una verdad filosófica" 5 . Una verdad filosófica, de existencia antes explícitamente prohibida, ahora admitida, tiene que ser introducida bajo una estructura de ficción. Como aquella "noble mentira" platónica en República. ${ }^{6}$

\footnotetext{
5 Alain Badiou, Lo que implica vivir, 5000 Ediciones, Córdoba, p. 96.

6 Platón, Rep. II, 382b-383c
} 


\section{Recensión: la cuestión de la ideología en contexto}

La filosofía de Badiou es, quizás con la excepción de Husserl, de las pocas que apela positivamente al término Idea después de la invención del término ideología. La de Badiou es la primera, sin embargo, en conservar esa palabra una vez que el vocablo "ideología" ha caído en un descrédito tal que hoy es sinónimo de anacronismo, cuando no de caducidad o de politiquería trasnochada. Ciertamente, no se trata de algo casual. Al dictamen del fin de la historia realizado por Francis Fukuyama, se le asocia una crítica a la época que elevó el mentado concepto de historia al rango de clave explicativa de todo proceso político humano. En esa crítica, dirigida directamente contra las experiencias emancipatorias que en el planeta habían ocurrido durante los años sesenta y setenta, estaba incluido un ataque a los modelos teóricos que les habían dado soporte. Una de las primeras operaciones de este ataque consistió en utilizar el término "ideología", pensado intensamente por y contenido en aquellos modelos teóricos, como equivalente a cada uno de estos modelos, o el conjunto de ellos tomados en conjunto. Así, por ejemplo, el edificio teórico marxiano se convirtió en "la ideología marxista" o en "la ideología comunista". Esta operación permitió consumar al mismo tiempo un doble movimiento: desbancar el privilegio teórico de una discusión en torno a la ideología y reducir un desarrollo teórico-político fértil a uno de sus aspectos parciales.

El segundo momento de este ataque se consumó en la calificación negativa del concepto de ideología. Este suele aparecer definido, o bien como un discurso falaz, o bien como una forma de sujeción que atentaría contra las formas de libertad individual. Estos dos argumentos que vuelven a la ideología algo pernicioso tienen su origen, no obstante, en algunas de las definiciones clásicas de la ideología que se han formulado incluso desde la izquierda (sobre todo aquella que la retrata como un bloqueo directo de la libertad humana). Se trata entonces de un gesto de torsión, más deliberado que azaroso. Es, en definitiva, una cierta victoria del capitalismo la que ha impulsado este estado de cosas. Su éxito puede medirse no sólo en la distancia que media ya entre nosotros y la posibilidad misma de su inserción más o menos conducente en el discurso mediático sino también en que los llamados teóricos post-marxistas han abandonado casi por completo su uso. A veces lo sustituyen 
funcionalmente por otros; otras veces lo eluden sin siquiera rodearlo.

Eagleton, en su canónico estudio Ideología, se pregunta: “¿Cómo explicar este absurdo? A qué es debido que en un mundo atormentado por conflictos ideológicos la noción misma de ideología se haya evaporado sin dejar huella en los escritos posmodernos y posestructuralistas?" $\mathrm{Y}$ la respuesta general que da a lo largo del libro es que se trata de un anudamiento entre tres doctrinas clave del pensamiento posmoderno: (1) el rechazo a la noción de representación; (2) un escepticismo epistemológico que impediría identificar cualquier forma de conciencia a lo ideológico y (3) una reformulación de la relación entre racionalidad, intereses y poder, que torna redundante el concepto de ideología sin más.

Más allá, o más acá, de esta tríada, el foco de atención de Eagleton está puesto en la estructuración del llamado pensamiento posmoderno, que tiende a ver en toda ideología un producto "teleológico, totalitario y con raíces metafísicas". Lo curioso, va a señalar Eagleton, es que "esta ideología del «fin de la ideología» es que tiende a concebir la ideología de dos modos bastante contradictorios, como algo ciegamente irracional y excesivamente racionalista (sic) a la vez". Estos dos modos, además, se hallarán medianamente replicados en el interior de la teoría marxista de la ideología, que el autor agrupará en dos vertientes.

Una tradición central, que va de Hegel y Marx a Georg Lukács y a algunos pensadores marxistas posteriores, se ha interesado más por las ideas de conocimiento verdadero o falso, y, en ese marco, por la noción de ideología como ilusión, distorsión y mistificación. Otra tradición de pensamiento alternativa, por su parte, ha sido menos epistemológica que sociológica, y se ha interesado más por la función de las ideas dentro de la vida social que por su realidad o irrealidad, o por su acuerdo o distancia con algo así como lo real. La herencia marxista se ha anclado entre estas dos corrientes intelectuales.

Lo que de momento me parece más interesante en el esbozo de Eagleton -y lo que va a resultar más pertinente para pensar el dispositivo de Badiou en torno a este problema- es la intuición de que:

El abandono de la noción de ideología corresponde a un titubeo político más profundo de sectores enteros de la antigua izquierda revolucionaria,

\footnotetext{
7 Terry Eagleton, Ideologia, Barcelona, Paidós, 2005, p. 13.
} 
que frente a un capitalismo temporalmente en posición ofensiva ha emprendido una firme y vergonzante retirada de cuestiones «metafísicas» como la lucha de clases y los modos de producción, la acción revolucionaria y la naturaleza del estado burgués. ${ }^{8}$

Como sabemos a esta altura, Badiou, aun perteneciendo a la época que describe aquí Eagleton, no es precisamente un pensador post-metafísico, motivo suficiente para pensar cómo se ubica en este cuadro, es decir, cómo localizamos en el mapa especulativo a alguien que se alza contra el fin de los grandes relatos, el fin de los sistemas, el fin de las políticas de emancipación y que, no obstante, abandona el arsenal léxico y conceptual del marxismo sin más, so pretexto de refundarlo.

Mi tesis central en este escrito es que la causa por la que Badiou pareciera haber abandonado su "preocupación ideológica" tiene que ver con un pasaje entre estas dos corrientes (desde un punto de vista que toma la ideología como campo de disputa hacia uno donde la ideología es todo lo que no es ciencia). Dicho pasaje coincidiría además con el momento de torsión de su filosofía que identificamos en la década del ochenta, relativo también al balance que aplica sobre el marxismo. Allí mismo, se produciría diagonalmente otro pasaje, coincidente en parte con el primero, entre un uso/producción de ciencia proletaria con propósito emancipatorio a un uso/producción de un tipo de ciencia burguesa, que no osa decir su nombre. La condición de posibilidad de este último reside en el primero, pues para una de las formas de hacer pasar inadvertido el cambio de posición de clase en ciencia es desbancar la posibilidad misma de que existan como tales, y oponer de golpe la ciencia tomada en su totalidad a todo lo que sería mera producción ideológica.

De momento, con prescindencia del sentido equívoco que pudiera adquirir el término "ideología", podríamos avanzar la pregunta directriz de este breve estudio. Se trata de una pregunta que nada tiene de inédito, pero que sin embargo vuelve a estar a la orden del día: ¿Qué función cumple el problemaideología en relación con la puja, antiquísima, entre filosofía y política? Quizás nuestro propósito último sea desentrañar si existe una relación -y de qué tipoentre una filosofía de la Idea y el mentado problema-ideología. En principio, no puede tratarse de una mera coincidencia lingüística.

8 Ibid., p. 14 
Si revisamos el marco general en el que se recorta esta pesquisa, la cuestión de la ideología se adivina además como uno de los puntos sobre los que consideramos que la filosofía debe rearmarse si se quiere retomar la senda materialista. Para poder recomenzar, esta filosofía, otra vez, como siempre, como cada ocasión en que ha sido amenazada en su existencia misma o en sus aspectos emancipatorios centrales. La cuestión de la ideología sería entonces el problema filosófico de la ideología, pero, sobre todo y más profundamente, el de cómo opera -o puede operar-ideológicamente una filosofía.

Así, estamos también ante el viejo problema de la filosofía y su lenguaje, es decir, de cómo transmitir y enseñar un mensaje filosófico. Es notable cómo el paradigma que intrincaba filosofía y pedagogía ha ido cediendo terreno a manos de otro, donde la filosofía es o bien una técnica con pretensión científica o bien una especulación conformada para expertos. La pedagogía, por su parte, ha quedado en reductos académicos y laberintos burocráticos, bastante herméticos también.

Una de las deudas más grandes de la filosofía contemporánea con Badiou se ubica en este preciso punto. Él más que nadie ha puesto el acento nuevamente sobre la voluntad enseñante de la filosofía. $\mathrm{Y}$ aunque en esta prevalencia luego veamos que se esconde $-\mathrm{O}$ se vehiculiza- la capitulación respecto del marxismo, no deja de ser crucial a la hora de pensar la relación entre ideología y política.

La repetición de aquel leitmotiv platónico-socrático de la "corrupción de los jóvenes" no puede ser casual. Implica, por un lado, la reposición del gesto inaugural de la filosofía como disciplina pedagogizante, cuya palabra está consagrada a prorrumpir en la pólis, y, por otro, su destinación a los jóvenes; ella tiene una vocación de futuro, y eso es algo que ha permanecido invariante a lo largo de los años del pensamiento badiouano. Podríamos decir que la verdadera invariante comunista que encontramos dentro de su reflexión es la confianza en la juventud y su deseo, abierto y honesto, de que el trabajo sea continuado por otros. En una entrevista de los años sesenta, un Badiou de corta edad conversa con los maestros Foucault, Canguilhem, Dreyfus, Hyppolite, Ricoeur. Allí dice, como quien deja caer las palabras, que enseñar filosofía es la única manera de volverla posible, de preservarla de sus enemigos. Creemos que de esto es de lo que hablamos cuando referimos al problema de fondo de este libro, a su marco marxista de referencia aquí mayoritariamente excluido, del que éste no es sino un primer paso. 
Es que la enseñanza de la filosofía y la filosofía misma no son separables. Los primeros filósofos lo sabían perfectamente. Heráclito era ante todo un guardián iniciático que quería torcer el sentido común en favor de una palabra elevada. Parménides relata a los mortales aquello que la diosa le ha revelado. Fue Platón, sin embargo, quien institucionalizó el sentido de este vínculo indisoluble. Es él quien convirtió la filosofía en una tarea educativa de largo aliento. Su filosofía toda podría pensarse como el establecimiento -escalonado, persuasivo y muchas veces velado- de un programa de formación para los aspirantes a filósofos. Este programa era además una enseñanza contra la paideia dominante. Era una contra-pedagogía. Es probable que lo más profundo de lo que Badiou llama su gesto platónico sea la instauración de una nueva contra-pedagogía, que se acopla o se identifica con una ideología subversiva, contra aquella dominante.

Una de las necesidades de esa contra-pedagogía es el desarrollo de una ética. Badiou va a requerir de una forma del discurso filosófico que predisponga a quienes aún no viven "una vida verdadera" a hacerlo. Y esto es lo que tiene que ser bautizado - de manera ideológica, claro está- como una ética.

La Ética de Badiou se concentra en dos puntos. Por un lado, en el despliegue de un diagnóstico crítico del mundo contemporáneo y, por otro, en el intento por definir qué sería una ética deseable en dicho mundo. Digamos para abreviar que la ética de Badiou es en el fondo una arenga para que vivamos consagrados a las verdades y que es esta consagración la que caracteriza a toda vida buena. Ahora bien, una lectura atenta vuelve a hacer inevitable empezar a pensar en la política. Casi de inmediato. No podría ser de otro modo cuando lo primero que tenemos es una descripción planetaria en donde lo que falla es la democracia, el paradigma de los derechos humanos, y donde lo que se pone a circular bajo el nombre de "ética" es, para el propio Badiou, un dispositivo (contra)ideológico. Pero también porque el propósito de un llamamiento general al interés y al apasionamiento por un acontecimiento erótico, científico o artístico, difícilmente puedan constituir la piedra de toque para subvertir el orden mundial que Badiou rechaza. Más allá de la ética de las verdades quiere decir para mí, ahora mismo, reconocer su necesariedad, saludar su vocación de interrupción de la languidez consumista y pasiva contemporánea, pero emprender un nuevo viaje, una nueva segunda navegación (exploratoria, claro) producida en gran medida por una situación que ha mutado, al menos ligeramente. No hay, dice Badiou, "sino una cuestión en la ética de las verdades: 
¿cómo voy, en tanto que alguien, a continuar excediendo mi propio ser? ¿Cómo ligar de manera consistente lo que sé con los efectos de la captura por lo nosabido?" Habrá que excedernos ahora una vez más. Más allá significa también acentuar el proceso por el cual "la ética de las verdades es siempre más o menos militante, combatiente"10. Más allá designa entonces, ahora, también, un más alla de la ética. Hacia la política. En situación. Y más allá de aquella propuesta por Badiou. Esto se vuelve más comprensible toda vez que asumimos que la insistencia ética de Badiou es ese signo de insistencia con el vacío, centro de la ética, que no es más que una exhortación subjetiva sin objeto.

Es probable que lo que estemos reflotando una vez más, es el problema de la relación entre filosofía y política. La filosofía está estrecha, esencial y preponderantemente ligada a la política, incluso más de lo que el propio Badiou estaría dispuesto a confesar. La equipolencia de las condiciones es sostenida en general con demasiada dificultad, incluso en términos biográficos.

Y estamos hablando sólo de la fuerza de esa relación (política/filosofía) que se arremolina por todos lados y gana terreno. Si además agregamos a esto lo que venimos de decir acerca del concepto de historia, notamos que la exigencia de afianzar la relación entre política y filosofía se vuelve cada vez más acuciante.

Repensar la cuestión de la ideología, en este marco, es en el fondo tratar de pensar, otra vez, la cuestión del sujeto. Del sujeto frente a y en la formación social. Del sujeto en-situación-de-acontecimiento, diría Badiou, que no coincide con esa formación social proveniente del repertorio marxiano porque es uno de sus puntos de distancia. El posicionamiento del sujeto frente a lo que ocurre en el mundo, lo que ve y lo que no alcanza a percibir, es eso que Badiou no deja de explorar. Ahí está su tratamiento velado del viejo tema de la ideología. Él escoge un nombre preciso para pensar esa disposición subjetiva: ética. Y la califica no casualmente como "un dispositivo ideológico". ${ }^{11}$

Ya no es "probable", que estemos reflotando el problema de la relación entre filosofía y política. Es evidente. Y así, en esa línea, hay que reflotar lo que de central esta relación tiene, según consideramos, después de Marx. ¿Por dónde podemos comenzar?

\footnotetext{
${ }_{9}^{9}$ Alain Badiou, Ética, Buenos Aires, Nueva Visión, 1995, p. 130.

${ }^{10}$ Ibid.

${ }^{11}$ Ibid., p. 8.
} 


\subsubsection{Badiou y Althusser bajo la forma del "traspaso".}

Hay un nudo, digamos, muy tratado, suficientemente utilizado por la tradición de izquierda para recriminar y descalificar a pensadores y hombres y mujeres de la política. Quizás se trate de el nudo, en lo que concierne a la cuestión de la ideología en la teoría marxista. Tiene que ver esencialmente con la intersección entre el saber y el sujeto. Si la ideología es ese vínculo privilegiado -consciente o no- del sujeto con el saber que condiciona sus prácticas sociales e intra muros, entonces la forma que adquiera esta relación cuando se trata del sujeto político colectivo, es capital. La conciencia es, en principio, el estado en que el sujeto cobra noticia de algo cuya forma es flexible pero determinable, de algo preciso, ante los ojos. El presente es el tiempo de la conciencia. La memoria es su prolongación hacia el pasado, en continua función presentificante. El nudo se construye con la relación imposible entre lo que el sujeto sabe, lo que no sabe y lo que los otros saben sobre aquello que no sabe (e incluso por sobre lo que cree que sabe). Así, el gesto de trasponer a otro un saber del que su supone carece es una forma de estructurar una falta. En política, la relación entre el acto de la suposición de aquello que un sujeto que no sabe y el acto de detentar dicho saber -muchas veces idénticos- establece un pacto de asimetría. Quien (cree que) sabe lo que hay que hacer, disminuye inevitablemente en algo a su otro. Y pretende dirigir. Es el rol que históricamente han asumido las vanguardias. $\mathrm{Y}$ de Althusser a Badiou, con diferencias de acento, pero en sintonía con una larga tradición heterodoxa de izquierda, existe una crítica a este esquema asimétrico entre quienes detentarían el saber-poder político y quienes deben dejarse conducir. El caso más espinoso, sin dudas, es el de Althusser, quien sin claudicar a su compromiso con el Partido (el PCF), mantuvo, aparentemente sin vacilaciones, una crítica incesante a esta idea dirigista. En Lo que no puede durar en el Partido Comunista, señala que el "pseudoprincipio" que dice que "la toma de conciencia nunca es espontánea", "suena excesivamente a ganas de recordar unas prerrogativas del partido sobre el movimiento obrero para señalar que es el partido (su dirección) quien detenta la conciencia verdadera, en relación con la cual la conciencia de los trabajadores 
está a menudo retrasada". ${ }^{12}$

En este texto de 1978 -es decir, luego de la experiencia crucial del Mayo Francés-, Althusser emplea una suerte de método de escritura reticente al modo del libertinismo erudito. Los títulos y subtítulos son más lacerantes y precisos que el resto del texto. A "Cómo tratar el error en política" le siguen "La organización: una máquina para dominar", "Los militantes, en una situación imposible", "Un modo de funcionamiento que hay que cambiar completamente", "Un partido calcado del aparato del Estado y del aparato militar", "Un pacto entre los dirigentes" y así prosiguen. Se dirigen contra el funcionamiento del PCF, su forma anquilosada de centralismo democrático, su incapacidad para revisar desvíos y su autocrítica al borde de la pantomima, su modelo militar de compartimentación y su estructura de democracia parlamentaria, que replican en última instancia "el modo de funcionamiento burgués de la política".13

Este golpe es similar al que Badiou le propina al Partido, pero en este último caso el derrotero político concreto ha estado más ligado a la exploración (primero hacia el maoísmo y luego en esa forma del autonomismo refinado de los ochenta) que al intento -como el althusseriano- de trastocar los vicios partidarios "desde dentro". Sin embargo, lo que aquí interesa es que ambos reconocen que el Partido no puede seguir ocupando el lugar del saber por contraposición a las masas. Y si la conducción ha conservado esta perspectiva caduca es gracias a una forma de cimentación ideológica. Existe, entonces, una forma ideológica que opera dentro del partido y, por lo tanto, en este caso, de la matriz de vanguardias. Althusser va a mostrar que esta ideología del partido "descansa en una emocionante confianza de los militantes en sus dirigentes, que encarnan para ellos la unidad y la voluntad del partido, heredero de la tradición revolucionaria nacional e internacional" $\mathrm{y}$, a su vez, paralelamente, "se da la explotación de esta confianza por medio de una ideología cuidadosamente formada y modelada por la dirección y sus funcionarios". ${ }^{14}$ Esto redunda en una identificación de la unidad del partido con su dirección. Althusser advierte que en la tradición marxista ni la unidad del partido ni el

12 Louis Althusser, Lo que no puede durar en el Partido Comunista, México, Siglo XXI, México, 1998, p. 15.

${ }^{13}$ Ibid., p. 65.

${ }^{14}$ Ibid., p. 38. 
propio partido constituyen un fin en sí mismo, sino que éste es "la organización provisional de la lucha de la clase obrera" 15 y no sirve "más que para la lucha de clase y su unidad se justifica al servicio de su acción". ${ }^{16}$ Luego nos vuelve a ofrecer, por vía indirecta, un rasgo capital de la ideología, de acuerdo con este período del pensamiento althusseriano:

Si el partido está paralizado y esclerotizado, su unidad podrá ser todo lo aparentemente perfecta que se quiera, porque mientras sea formal e inútil el partido estará cimentado, es decir, paralizado por una ideología esclerotizada e inmóvil. Si el partido está vivo, su unidad será contradictoria, y el partido estará unificado por una ideología viva, que será forzosamente contradictoria, pero abierta y fecunda. ${ }^{17}$

La ideología puede ser, entonces, algo polémico, brotante, que se divide en sí mismo y por sí mismo para dar paso a la novedad. Sin embargo, aun si la ideología es divisible, contradictoria y ebullente, el centro de la tarea política sigue siendo de un otro concreto, del otro dialectizado respecto de lo teórico, de algo que está antes de toda constitución subjetiva incluso: "Sin embargo, ¿qué hace que un partido sea vivo? Su relación viva con las masas, con sus luchas, sus descubrimientos y sus problemas", va a decir el maestro de Badiou. ${ }^{18}$

Digamos entonces que en el iluminismo vanguardista también hay una operación ideológica necesaria, que Althusser reconoce y de la cual reniega hasta cierto punto en la práctica; operación que Badiou no reconoce explícitamente, pero de la cual pretende alejarse (sobre todo con un pensamiento de la igualdad como postulado), y a la que ambos quedarían sujetos, menos por propia voluntad que por falta de una autocrítica certera, historizada y geopolíticamente precisa.

Hay, en esa enumeración en la que Althusser hace depender cualquier proceso político de la acción de las masas, una expresión, rara, «fuera de registro» retórico: "la prodigiosa sorpresa de mayo del '68". En todos los otros casos la expresión límpida, no calificada, da cuenta de un proceso objetivo que

\footnotetext{
${ }^{15}$ Ibid., p. 73 .

${ }^{16}$ Ibid., p. 74.

${ }^{17}$ Ibid., p. 73.

${ }^{18} \mathrm{Ibid}$.
} 
pareciera inscribirse en las fuerzas de la historia, pero sobre ese evento se nos dice que se trata de una "prodigiosa sorpresa". Justamente sobre el Mayo Francés, ocurrencia sobre la cual se va a producir la divergencia entre el Althusser-maestro y el Badiou-discípulo. Althusser clasifica esa ocurrencia casi en los términos badiouanos: algo inesperado, y con carácter milagroso. Es, diríamos, inequívocamente un acontecimiento.

Todo sucede pues como si ambos se montaran a una secuencia precisa de la historia de las ideas. Althusser comienza a anticipar aquello que será el núcleo del pensamiento propiamente badiouano, a la vez que Badiou, en sus trabajos más recientes comienza a balbucear, tal vez a su pesar, un nuevo acercamiento -que no dudó en calificar de pernicioso cuando se producía en la obra de Althusser- entre filosofía y política. Lo que aquí nos interesa es la posibilidad cierta de comprender esta especie de traspaso. Parece como si fuera el mundo, lo otro de la filosofía, lo que fuerza a asumir distintas estrategias para volver la filosofía posible. Es sobre esto que intentamos llamar la atención. Es esto también lo que denominamos estrategia de la filosofía, y de lo cual la ideología no es más que su matriz. Esto, por lo demás, es compatible con el esquema de condicionamiento - político en este caso- que formulan ambos autores.

Si en ambos casos las torsiones finales de sendos pensamientos parecen acoplarse sin muchos problemas al pensamiento que les ha sucedido o les debería suceder (en el caso de la filosofía presente) es menos por el azar o incluso la discusión interna entre los pensadores que por la presión que ejerció el mundo que les ha sido contemporáneo. Es decir: si el Althusser de fines de los setenta comienza a mostrar ciertas reservas nada menores sobre la cuestión del partido y comienza a mostrar un léxico más propicio al pensar del acontecimiento es porque la experiencia del estalinismo, de la Revolución Cultural y del Mayo Francés -entre otros- están influyendo. De igual modo, el Althusser de los ochenta -pienso esencialmente en el Althusser del materialismo aleatorio- avisora sin dudas la necesidad de una meditación en torno a la ontología, que Badiou retomará como proyecto vertebrante de su filosofía. Una ontología de la singularidad, minuciosa, que Althusser asociará a una corriente subterránea de pensamiento que ha sido reprimida por ser considerada peligrosa. Una ontología materialista pero fuera del registro de Marx, o más allá de él, pero no al modo de una prolongación necesaria como la que antes era requerida, sino más allá, en el sentido de un agujereamiento, de 
una salida, si es que es posible. Una ontología de la que intentará no salir, y a la que le costará enormemente renunciar. En Lo que implica vivir, dirá, sin ambages, que sobre lo que no hay que ceder es sobre el tratamiento ontológico (y sobre la muerte de dios). En cualquier caso, lo único que proponemos someramente aquí es la posibilidad de revisar si es Z-F el mejor dispositivo matemático para dar cuenta del ser-en-tanto-que-ser, o bien si existe otro más potente y acorde a las demandas políticas del mundo actual.

Retornemos. Estábamos en el primer traspaso. El que el último Althusser se encuentra con un Badiou ya crítico del marxismo ortodoxo. En ese encuentro, se halla este tardío materialismo ontológico que plantea Althusser y que resume como:

Un materialismo del encuentro, así pues, de lo aleatorio y de la contingencia, que se opone como un pensamiento muy diferente a los distintos materialismos que suelen enumerarse, incluso al materialismo comúnmente asociado a Marx, Engels y Lenin que, como todo materialismo de la tradición racionalista, es un materialismo de la necesidad y la teleología, es decir, una forma transformada y encubierta de idealismo. ${ }^{19}$

Lo que pareciera estar en juego en esta propuesta, además de la necesidad de un nuevo pensamiento ontológico por causa de la muerte de dios en proximidad con una línea post-metafísica, es el viejo problema del azar opuesto a la necesidad. Este azar que Badiou incluirá en aquello inconsistente que no se deja apresar, o lo hace a duras penas, por una estructura-deconsistencia, o cuenta-por-uno. "El «materialismo» de la lluvia, la desviación, el encuentro y la toma de consistencia", ${ }^{20}$ dirá por su parte Althusser. La intuición fundamental de que la filosofía es un vacío operatorio, cuya forma de acción se asocia a la recepción y demarcación del campo político sigue viva, pero se le agrega una diferencia sutilísima: la filosofía renuncia a dotarse de un "objeto", dice, "para partir sólo de nada (rien), y de esa variación infinitesimal y aleatoria de la nada que es la desviación de la caída" 21 . Una variación mínima y aleatoria de la nada, que es centro de una ontología materialista, pensable en segundo término por la filosofía. No hace falta insistir demasiado en el aire de

${ }^{19}$ Louis Althusser, Para un materialismo aleatorio, Madrid, Arena, 2006, p. 31.

${ }^{20}$ Ibid.

${ }^{21}$ Ibid., p. 40. 
familia que este planteo tiene con lo que Badiou nos proporcionará en su etapa más propia, más propositiva, aquella de El ser y el acontecimiento. Y aunque él ha reconocido públicamente que se trata de su libro más "raro", no deja de ser también el libro a través del cual su obra ha sido leída y la que abre paso a su pensamiento más sistemático.

Ahora bien, si asumimos que esto mismo puede estar sucediendo con Badiou en la actualidad (precisamente por los indicios a los que nos referíamos más arriba), en esta sucesión lo que queda por ver es cómo se sale, cómo se profundiza y se trasciende el gesto que Badiou está ofreciendo en esta última etapa de su obra, aún inconclusa.

Sabemos una cosa: esta forma de salir es, como enseñó Badiou, extraer las consecuencias todavía inesperadas de lo que nuestros antecesores nos dan que pensar. Eso es también una forma de la fidelidad. Y dicha fidelidad no es, no puede ser, nunca, una repetición sin más. Sabemos, por Althusser sobre todo, que una filosofía es lo opuesto de un dogma. El tono filosófico que este libro pueda tener depende entonces de su capacidad relativa para formular, siquiera provisoria y parcialmente, un reflejo más allá de Badiou. $\mathrm{Y}$, sin embargo, más allá designa también el sitio en donde Badiou no puede ser el término omnipresente, pero sí el que habilita a pensar el mundo, aquel que se impone: como condición necesaria de toda filosofía materialista; como espacio que impide la totalización vulgar de lo que se formula discursivamente. Y todo esto, en la línea de esa filosofía materialista que todavía buscamos fundar (o continuar). Hago mías aquí y ahora las actuales palabras de aquel joven Badiou de El (re)comienzo:

Para concluir, quisiera subrayar la necesidad absoluta, y al mismo tiempo el riesgo de este (re)comienzo del materialismo dialéctico. Ante todo, debo decir que en mi opinión no existe actualmente otra posibilidad, si se quiere poder bablar al menos de aquello a través de lo cual la realidad silenciosa (silenciosa en la teoría) nos interpela y nos hace "portadores" de funciones históricamente determinadas. No existe otra posibilidad si queremos pensar lo que constituye nuestra coyuntura política. ${ }^{22}$

Y así como Althusser volvía a Badiou portador de esa verdad del

22 Alain Badiou "El (re)comienzo del materialismo dialéctico", en Cuadernos de pasado y presente, núm. 8, Córdoba, 1969, p. 33. 
marxismo que es su recomenzar incesante -algo que no cede en ninguna etapa de la filosofía badiouana-, él mismo asumiría, con su maestro, también ese requerimiento general de recaer en una ontología y una de la multiplicidad y de la contingencia.

Pero hay que sopesar concienzudamente la forma de este montaje entre Badiou y Althusser. Hacerlo es casi una necesidad surgida de la vocación de nuestra investigación marco, que tiene como propósito rehistorizar la filosofía y volverla a poner bajo los supuestos de la verdad-marxista.

Starcembaum ${ }^{23}$ sostiene que hay cuatro etapas en la relación entre Badiou y su maestro. La primera, interrumpida con el acontecimiento de 1968, en donde Badiou está completamente influenciado por el althusserianismo. Una segunda, abierta en ese preciso momento y que corre hasta fines de los setenta, marcada por la crítica maoísta a Althusser. La tercera, aquella sobre la que hemos insistido en más de una ocasión, es la que corresponde a la década del ochenta, desarrollada en oposición al althusserianismo. Finalmente, una cuarta, iniciada en la década del noventa, en la que Badiou esbozaría un "rescate" de Althusser.

Aunque cabría matizar en cierta medida esta periodización -sobre todo en lo atinente a lo que significaría la "oposición" de la década del ochenta- es útil para pensar que las orientaciones del discurso filosófico derivan, sino de la afectividad primaria de dos personas, al menos del mundo, más amplio o más restringido, que los circunda. Así, comenta Starcembaum, "la adjudicación a Althusser por parte de Badiou de un lugar en el contexto político-intelectual de mediados de la década de 1960 se inscribe en el marco de una concepción del estado del movimiento comunista internacional". En este período, signado por el ataque al dogmatismo de la conducción del PCF, los textos fundamentales son El (re)comienzo del materialismo dialéctico, El concepto de modelo (cuya publicación fue precisamente aplazada por la irrupción del Mayo Francés) y De la ideología, todos gobernados por la conceptualización marxista y la necesidad de evitar cualquier desvío teoricista o, lo que es equivalente a estas inquietudes, la fidelidad a la pregunta althusseriana de qué es una filosofía marxista.

Todavía en el corazón de esta vigencia, en El concepto de modelo, Badiou gira en torno a un tipo de materialismo que declarará años más tarde haber

\footnotetext{
${ }^{23}$ Marcelo Starcembaum, “Alain Badiou lector de Althusser”, en Revista Laberinto, núm. 37, 2012, p. 1.
} 
abandonado: uno propio de la materialidad de las marcas y de los símbolos, exposición de lo real que se sustraería al dato empírico tanto como a los objetos intuidos por la conciencia. El abandono se hace en favor de un materialismo que el filósofo no duda en calificar de "ontológico", que dona un privilegio a la evidencia del "hay" y se funda en la marca del vacío. La razón de este pasaje proviene a su vez de una ruptura con la epistemología dialéctica de Althusser.

Sin embargo, este "pasaje" -como lo llama Badiou-, no deja de tener consecuencias para la reconstrucción que nosotros intentamos montar aquí, que oscila cada vez entre las posibles definiciones de ideología y su correlato con aquello que cubre, o descubre, que posibilita u oblitera, que no deja de ser lo real, y que en esta investigación viene identificándose, casi por hipótesis, con cierta forma de la materialidad económico-política. De esta correlación surgen los distintos materialismos posibles. En ese contexto, cabe pensar lo que Badiou desplegaba en este libro, atravesado literalmente por el Mayo Francés, y todavía cobijado por la preocupación althusseriana de la posible elaboración de una producción teórica con posición proletaria en el seno del capitalismo.

La organización del proletariado, todavía a la orden del día para Badiou en aquel entonces, era inescindible de la práctica teórica. Y para conseguir estos objetivos era necesaria "la preparación ideológica de las masas", es decir, "una vasta campaña vasta de rectificación ideológica". Este libro entonces designará también un momento en ese nudo entre ideología y real que describíamos. Esa preparación a la que se refiere no puede darse por fuera del propio dispositivo del que estamos hablando en este caso: el matemático. Hemos usado el montaje en la relación discípulo-maestro para poder introducirnos en el desde una perspectiva histórica.

En aquel entonces Badiou sostenía, en un lenguaje que no abnegaba del marxismo, pero tampoco de cierto aire francés de época, que "un sistema formal es una máquina matemática, una máquina para la producción matemática y ubicada en el proceso de esta producción", ${ }^{24}$ siendo el instrumento científico, él mismo, "un resultado científico". Esta última cláusula otorga garantía de inmanencia al dispositivo pensante del que se trata aquí: nada está fuera en el proceso de producción, nada externo es requerido para su funcionamiento, de modo que la retroalimentación es su ley. En ese sentido, el concepto de modelo "no designa un afuera que hay que formalizar, sino un

${ }^{24}$ Alain Badiou, El concepto de modelo, Buenos Aires, LBE, 2009, p. 105. 
material matemático que hay que experimentar". 25

Lo que aquí nos interesa es la proximidad no accidental entre el concepto marxista de producción y el del dispositivo matemático. El materialismo de esta época se cifra en el hallazgo de que aquello que inscribe lo real es, a su vez, un medio de producción, conjugable -aunque Badiou no lo diga- con una fuerza de trabajo intelectual. Los dispositivos escriturales son, así, "medios de producción, en el mismo sentido en que lo son, para la física, el tubo de vacío o el acelerador de partículas". ${ }^{26}$ Badiou, en el nudo entre ideología y real al que nos referíamos más arriba, presenta en una primera instancia una lectura ideológica de un dispositivo científico, revelando su naturaleza contingente, pero sin ceder a la tentación meramente crítica. Que el dispositivo sintáctico sea "teoría materializada" constituye el centro de este proyecto de confrontación ideológica. Implica, en primer lugar, un pensar de la producción teórica en términos estrictamente inmanentes. Por eso es que Badiou va a poder decir más adelante que "la inteligencia de los montajes formales matemáticos se despliega en la práctica conceptual de las matemáticas mismas". ${ }^{27}$ Refiere, en segundo término, a una forma concreta de la materialidad, al mismo tiempo sustraída a la equivocidad y al artificio noético. De ahí que pueda preverse que su proyecto se erige frente a un sistema de dominación específico, que no duda de designar como "epistemología burguesa":

El discurso de Carnap, como el de Lévi-Strauss, es una variante de la epistemología burguesa. En la combinación, que aquí exhibe, de nociones empiristas relativas al "problema del conocimiento" y de procesos científicos tomados de la lógica matemática, combinación que define la categoría filosófica de modelo, la ideología es dominante y la ciencia, sometida. $^{28}$

La cuestión será aquí disputar el concepto de modelo así definido por esa epistemología. Existe una epistemología materialista y ésta describe una doctrina de la producción de los conocimientos científicos, en cuya evolución

\footnotetext{
25 Ibid., p. 111.

26 Ibid., p. 105.

27 Ibid.

28 Ibid., p. 111.
} 
hallaríamos el concepto de modelo como un "índice epistemológico, por cuanto se descifra allí la dialéctica experimental de la producción matemática y se arranca a esta última de su condición idealista de conocimiento puro, formal, a priori". ${ }^{29}$ "Modelo" designa aquí un espacio privilegiado para esa disputa. Es el nombre que provee un acceso a otro término caro del Badiou de la época, y central para nosotros, el de historia. El modelo expresa "la causalidad retroactiva del formalismo sobre su propia historia científica, historia conjunta de un objeto y un uso", 30 es decir, una instancia que denota el carácter experimental, abierto y eminentemente práctico de la ciencia, instanciado en este caso en el dispositivo formal matemático. Es "la red cruzada de retroacciones y anticipaciones" 31 de la historia de la formalización la que teje esta historia.

Sucede que Badiou está al borde de decir que incluso las matemáticas, paradigma de limpieza y neutralidad, se nutren del trabajo -heteróclito, no necesariamente acumulativo- de los científicos, pero, en definitiva, del trabajo a secas. Es éste y no otro el nudo de todo materialismo que se precie de reconocerse en la filiación marxista. Badiou está próximo a este nudo. Que Badiou esté tan cerca y a la vez que marque esta pequeña distancia a partir de la ausencia mínima (mínima por cuanto los conceptos de producción y de historia están, en cambio, aceitadamente en marcha en esta epistemología materialista) habla del despuntar de la divergencia con el marxismo ortodoxo pero no deja de ser un indicador de: (a) lo que significa el materialismo en aquel momento histórico para Badiou; (b) lo que lo separa de su actual definición de materialismo, menos ligada a estas ideas que a una idea abstracta y secundaria respecto de otras prioridades especulativas y, finalmente, políticas.

Lo que hay que correr, en este caso, es una barrera ideológica. Y se trata de una barrera ideológica que tuvo como objeto precisamente el abandono de la centralidad de la ideología -y luego su obliteración-, así como aquella de la historia, como venimos de mostrar. Sendos abandonos y desplazamientos son índice de la capitulación badiouana respecto del programa marxista. De ahí el trastocamiento de la ideología bajo el signo de la Idea platónica contemporánea, evidencia de este bloqueo. De ahí la posibilidad de decir que,

\footnotetext{
${ }^{29}$ Ibid., p. 75.

30 Ibid., p. 123.

31 Ibid., p. 124.
} 
"en el fondo, para comprender bien la cansada palabra «ideología» lo más simple es quedarse cerca de su conformación: es ideológico lo que procede de una Idea". 32

Mi tesis de fondo -tácita, pero latente en esta investigación- es que la paulatina desaparición del concepto de ideología en el esquema de Badiou es obra de una sustitución por el concepto de Idea, que no coincide exactamente con aquel (la prueba reside en este intento tardío de (re)definición del primero en términos del segundo), y que esta lenta sustitución ha sido acompañada por un viraje en la concepción de filosofía, que ha pasado de ser una lectura abiertamente marxista sobre los predecesores y el mundo político, a una ideología (ella misma con anclaje en una ciencia con punto de vista burgués). Primero autoposibilitándose como tal, en una época que reclamaba su fin, y luego rearmando la factibilidad del cambio en el mundo. La misma ideología que hoy bloquea el cambio radical (marxista) que vino a reabrir.

En efecto, en la obra de Badiou todo se presenta como si asistiéramos a un cambio de paradigma en el triángulo conformado por la ideología, la filosofía y la ciencia. En un primer momento existe una ideología proletaria, distinta de la ciencia. La ciencia, determinada como un materialismo histórico cuyo propósito es revelar las reales condiciones materiales de la existencia, está conectada pese a su diferencia con aquella ideología proletaria. La filosofía, por su parte, cumple la función -althusseriana- de intervenir demarcando la diferencia entre aquel saber que correspondería a esta ciencia y aquel que, por el contrario, reproduce el aparato de dominación burgués. Luego, en un segundo momento, atravesado el desplazamiento ubicado entre la Teoría del Sujeto y El ser y el acontecimiento, la ciencia, ya convertida sin ambages en la axiomática de conjuntos de Z-F, cumple la función de tematizar el "hay" de la ontología. Es decir, estamos ante el relanzamiento antiescéptico y antirromántico de la filosofía, pero al costo de inhabilitar dos elementos cruciales: lo histórico atinente a la filosofía y el punto de vista proletario de una ciencia, distinto de la ideología. El borramiento del concepto de ideología no es sólo un abandono del léxico marxista; es la condición de posibilidad de disimular que lo que se ha hecho es optar por un punto de vista burgués en ciencia, por cuanto se reconoce una "mera historicidad" del dispositivo

32 Alain Badiou, L'Hypothèse communiste. Circonstances 5, Paris, Nouvelles Lignes, 2009, p. 189. [La traducción es mía] 
matemático, pero se desoye su carácter constitutivamente material, es decir, producido por ciertos medios y relaciones de producción. Hemos perdido terreno cuando creíamos que lo ganábamos.

Y esto no deja de repercutir en la cuestión esencial del sujeto (político), pues no deja de ser una capitulación también reconducir casi toda su política hacia aquello que antes descalificaba. En efecto, en De la ideología, leíamos:

Ni los esclavos ni los siervos han podido dotarse jamás de otra cosa sino de reagrupamientos transitorios, generalmente armados, ligados a la particularidad de una revuelta. El aplastamiento de la revuelta era siempre ineluctablemente la dislocación e inhibición de todo principio de organización. La organización era contemporánea de la propia revuelta y no podría sobrevivirla: organizaciones de masas, por tanto, y no de clase. ${ }^{33}$

Entonces, aun si Badiou poseía ya la intuición fundamental de que el centro de gravedad del sujeto político estaba en la organización, qué puede decirse de la distancia operada sobre esta idea de que es la organización de clase, dialectizada con aquella de masas, la que posee privilegio organizativo y eficacia real- en el mundo político. De ahí que Badiou pueda decir también que "[e]l proletariado es la primera clase explotada en la historia en estar dotado de organización de clase específica". ${ }^{34}$ Sin historia, una vez más, perdemos el eje de lo que encarna el verdadero proceso de lucha emancipatoria. El resto, son sólo intentos vacuos y condenados a su desaparición. Ese resto -y no máses lo que Badiou nos ofrece en El ser y el acontecimiento. ¿Cómo podría interpretarse este paso sino como una capitulación? ¿Cómo no hacerla flotar sobre la discusión más profunda con Althusser, que aun ya despuntando en $D e$ la ideología no acaba sino por cristalizarse en El sery el acontecimiento y en $\dot{\imath}$ Se puede pensar la politica??

Ceder, como se ha cedido la centralidad del proletariado es dictaminar la irrelevancia de la ideología. Aquí podemos pensarlo a la inversa: la ausencia de la ideología en los términos originalmente planteados -o su subsunción a esta forma pre-marxista que la vincula a la Idea- es una manifestación de la pérdida de la potencia (lógica) emancipatoria del sujeto identificado bajo su única forma de eficacia real (el proletariado):

33 Alain Badiou, De la ideología, p. 49.

34 Ibid. 
No existe ya por lo tanto la ideología dominante y lo que la resiste de enorme e invariable. Existen dos ideologías: burguesa y proletaria. Ciertamente, la ideología está siempre escindida y todo es reflejo de clase. Sin embargo, el proletariado es lo que da forma a esta escisión, divide la lógica misma, y somete irreversiblemente el pensamiento al reconocimiento de su propia escisión. El proletariado no es el inventor de la resistencia ideológica: es el primer lógico. ${ }^{35}$

Cuando el "primer lógico" ha dejado paso a la dureza del matema sin sujeto, anterior a todo sujeto, ya tenemos un primer paso hacia atrás. Cuando este matema sin sujeto es, además, no ya índice de la materialidad histórica de la producción sino residencia del presente absoluto de la ciencia. Cuando, además, esta intelección lógica se dirige no ya a la política sino al "hay" ontológico en general, la operación está completada.

$\mathrm{Y}$ hay que reparar aquí en que en el fondo estamos asistiendo a un corrimiento entre las dos grandes concepciones de ideología que aislaba Eagleton. Pasamos de aquella que enfrentaba a dos registros de lo mismo -aun si una tiene un cierto anclaje científico- pero con sentido opuesto (ideología burguesa e ideología proletaria), para alcanzar una versión que opone el matema, como ciencia, al ideologema romántico, sofístico, democrático de la contemporaneidad y que Badiou no se cansa de denunciar, incluso si no lo nombra demasiado como ideología. Que no lo nombre como tal no implica que no funcione de esa manera, sino más bien es un índice de la necesidad de erradicar el término para poder efectuar tranquilamente su propia operación de desplazamiento ideológico.

Y así, sucede al revés de la mayoría de los casos. El Badiou de los setenta podría ser tranquilamente un crítico lector del posterior (si seguimos suscribiendo a la senda marxista). Leamos el siguiente pasaje e intentemos no pensar que se trata de un ataque a las peripecias del pensamiento político badiouano de los ochenta:

Esta cuestión es materialista: y ella requiere que la potencia lógica del proletariado sea asignada a procesos objetivos. Para que el marxismoleninismo aparezca como realidad viviente, como lógica de la historia, es

35 Ibid., p. 59. 
preciso que su desarrollo esté orgánicamente ligado a la posibilidad de recoger, clasificar, sistematizar las ideas justas resultantes de las revueltas de masas, y de dirigir la lucha entre las ideas verdaderas y las ideas falsas en la esfera de la ideología. Estas condiciones son cumplidas mientras exista una capacidad permanente para superar la dispersión de las experiencias y para elaborar una fuerza subjetiva que no sea esporádica o ligada a un episodio particular de la lucha de clases, sino que opere como lugar de balance de la experiencia de todas las luchas sucesivas. 36

Imposible. Suena como una capitulación deliberada, consciente, completa. ¿Por qué esta resonancia? En el paso hacia el Badiou posterior estamos ante una maniobra calculada, donde la crítica al marxismo busca la posibilidad de hacer el discurso filosófico audible nuevamente, y con la máxima llegada posible. Allí ya resonaba esa intención tan omnipresente en los últimos diez años de la obra badiouana: corromper a los jóvenes. La pedagogía primó por sobre los contenidos programáticos de la política y por eso avanzamos que la filosofía, así dependiente de una ciencia burguesa, ha comenzado a operar como una ideología. Y no es poco, y no fue un paso necesariamente equívoco, pero ciertamente hoy es insuficiente, más si seguimos con aquella pretensión de volver la filosofía un objeto de circulación -mediata- en la sociedad.

En ese sentido, se puede pensar que, del mismo modo que Badiou sostenía en el Manifiesto que la filosofía pregonaba su muerte por una suerte de culpa por no haber anticipado o evitado el exterminio nacionalsocialista, hoy todavía pagamos las consecuencias del llamado "fracaso" de las experiencias socialistas. Lo notable es que Badiou, que lo advierte en el comienzo mismo de La hipótesis comunista y con menor énfasis en ¿Se puede pensar la política?, no logra salir del pathos de dicho fracaso y deja en exceso debilitado el programa marxista $\mathrm{y}$ algunas de sus intuiciones fundamentales, habida cuenta de que dicho fracaso es siempre relativo y de que la tarea de la emancipación humana está a la orden del día, como él sabía perfectamente al menos toda la década del setenta.

El caso de Badiou es singularísimo. Es lo opuesto a un derrotado; incluso los detesta. Vitupera cada vez que puede a sus viejos camaradas rojos que han capitulado. Positiviza la filosofía, autonomiza la política. Dice que esta última tiene todo por hacer y se empeña en que la juventud reciba este mensaje.

${ }^{36}$ Ibid., p. 48. 
$\mathrm{Y}$, sin embargo, desde la década del ochenta, nos ha dejado sin clases, sin ideología, sin historia, sin análisis económico del capital, sin lucha de clases, sin masas, sin revolución. ¿Cómo se escribe el marxismo -crítico- sin estos nodos? ¿Cómo hacer para saber dónde colocar el límite entre lo que todavía sigue vigente del marxismo y aquello que ha perimido?

Por eso, quizás, sea el filósofo entre los siglos: posibilitante, exige una salida que lo profundice. Nada hace pensar que esa profundización no pueda retomar algunos temas tan caros de la filosofía materialista, a riesgo de resutura. En Lo que implica vivir, ante la pregunta por cómo se imagina la filosofía después de Badiou, él responde: "Yo estoy convencido que, junto a otros, no hago más que abrir posibilidades". Para concluir un poco más adelante: "En consecuencia, la filosofía se hace para que la vida sea apasionante y no siniestra. Es su objetivo fundamental, aunque esto plantee un problema. Pienso que los tres dominios que creo haber abierto [el ontológico, el del condicionamiento, el de la subjetividad], van a continuar después de mî".

\section{Bibliografía}

-Althusser, L., Lo que no puede durar en el Partido Comunista, Madrid, Siglo XXI, 1978.

-Althusser, L., Para un materialismo aleatorio, Madrid, Arena, 2006.

-Althusser, L., La revolución teórica de Marx, Madrid, Siglo XXI, 1990.

-Althusser, L., Lenin y la filosofía, Buenos Aires, Nueva Visión, 1994.

-Anderson, P., El Estado absolutista, Madrid, Siglo XXI, Madrid, 1979.

-Badiou, A., La filosofía, otra ver, Madrid, Errata Naturae, 2010.

-Badiou, A., À la recherche du réel perdu, Paris, Fayard, 2015.

-Badiou, A., Second manifeste pour la philosophie, Paris, Fayard, 2009.

-Badiou, A., Lógicas de los mundos, Buenos Aires, Manantial, 2008.

-Badiou, A., Manifiesto por la Filosofía, Buenos Aires, Nueva Visión, 1990.

-Badiou, A., Condiciones, México, Siglo XXI, 2002.

-Badiou, A., El sery el acontecimiento, Buenos Aires, Manantial, 1999.

-Badiou, A., ¿Se puede pensar la política?, Buenos Aires, Nueva Visión, 1990.

-Badiou, A., L'Hypothèse communiste. Circonstances 5, Paris, Nouvelles Lignes, 2009.

-Eagleton, T. Ideología, Barcelona, Paidós, 2005. 
-Kolakowski, L., Las principales corrientes del marxismo, Madrid, Alianza Editorial, 1983.

-Starcembaum, M. “Alain Badiou lector de Althusser", en Revista Laberinto, núm. 37, 2012.

-Toscano, A. "L'expatriation du marxisme ou le tournant d'Alain Badiou", en Figures du marxisme, s/d.

Recibido: 5/2019. Aceptado: 9/2019 